\title{
O IMPACTO DA TAXA DE APROVAÇÃO EM DISCIPLINAS DE FÍSICA BÁSICA NO PERCURSO FORMATIVO DE ESTUDANTES NA GRADUAÇÃO EM FÍSICA
}

\author{
Júlio Akashi Hernandes ${ }^{1}$ \\ Universidade Federal de Juiz de Fora \\ http://orcid.org/0000-0001-9263-6310 \\ Paulo Henrique Dias Menezes ${ }^{2}$ \\ Universidade Federal de Juiz de Fora \\ http://orcid.org/0000-0002-3008-9830 \\ Giovana Trevisan Nogueira ${ }^{3}$ \\ Universidade Federal de Juiz de Fora \\ http://orcid.org/0000-0001-5735-4131
}

\begin{abstract}
RESUMO:
A cultura da reprovação é altamente alardeada nos cursos de graduação em física, seja pela suposta falta de preparo e maturidade dos estudantes, ou pela suposta complexidade das disciplinas introdutórias de Física e de Cálculo. O estudo apresentado neste artigo questiona esse pressuposto, a partir da análise da taxa de aprovação de estudantes em disciplinas de física básica na relação com o percurso formativo nos cursos de licenciatura e bacharelado em física. Trata-se de um estudo de caso realizado em uma universidade pública brasileira, conduzido na forma de uma pesquisa quantitativa, longitudinal, que analisou informações sobre disciplinas de física básica ofertadas no período de 2000 a 2019. Os dados foram organizados e analisados a partir de três eixos principais: número de matrículas na disciplina; número de alunos aprovados; e taxa de aprovação. Conclui-se que o desempenho dos estudantes nessas disciplinas não melhora com o tempo de permanência no curso, corroborando com a baixa eficiência dos cursos de graduação em física para formar novos profissionais. Os resultados indicam ainda a necessidade de reflexões mais amplas e aprofundadas sobre a organização curricular e a forma de oferta das disciplinas de física básica, que compõem os currículos dos cursos de graduação em Física, no sentido de formar mais e melhor.
\end{abstract}

Palavras-chave: Graduação em física. Taxa de aprovação. Disciplinas de física geral.

\section{ABSTRACT: \\ THE IMPACT OF THE APPROVAL RATE ON BASIC PHYSICS DISCIPLINES ON THE FORMATIVE TRAJECTORY OF STUDENTS IN THE PHYSICS GRADUATION}

The culture of failure is highly trumpeted in undergraduate physics courses, either due to the supposed lack of preparation and maturity of the students, or due to the supposed complexity of the introductory Calculus and Physics disciplines. The study presented in this article questions this assumption, based on the analysis of the approval rate of students in basic physics disciplines and its relation with the formative

1 Doutor em Ciências (UFJF). Docente do Programa de Mestrado Nacional Profissional em Ensino de Física (UFJF). Departamento de Física. E-mail: jahernandes@gmail.com.

2 Doutor em Educação. Docente do Programa de Mestrado Nacional Profissional em Ensino de Física (UFJF).E-mail: paulo.menezes@ufjf.edu.br.

3 Universidade Federal de Juiz de Fora (UFJF). Doutor em Ciências. Docente do Programa de Mestrado Nacional Profissional em Ensino de Física (UFJF). E-mail: giovana@ice.ufjf.br. 
trajectory in the bachelor and teaching degrees in physics. This is a case study carried out at a Brazilian public university, conducted in the form of a quantitative longitudinal research which analyzed information on basic physics subjects offered in the period from 2000 to 2019. The data were organized and analyzed from three main axes: number of enrollments in the disciplines, number of approved students and pass rate. We conclude that the performance of students in these disciplines does not improve with the length of stay in the course, corroborating the low efficiency of undergraduate courses in physics to train new professionals. The results also indicate the need for broader and more in-depth reflections on the curricular organization and the way of offering the basic physics disciplines that make up the curricula of undergraduate courses in Physics, in order to train more and better.

Keywords: Graduation in physics. Approval rate. General physics disciplines.

\section{RESUMEN:}

\section{EL IMPACTO DE LA TASA DE APROBACIÓN EN LAS DISCIPLINAS DE FÍSICA BÁSICA EN EL CURSO FORMATIVO DE LOS ESTUDIANTES EN LA GRADUACIÓN DE FÍSICA}

La cultura del fracaso está muy difundida en los cursos de licenciatura en física, ya sea por la supuesta falta de preparación y madurez de los estudiantes, o por la supuesta complejidad de las asignaturas introductorias a Física y Cálculo. El estudio presentado en este artículo cuestiona este supuesto, a partir del análisis de la tasa de aprobación de los estudiantes de las disciplinas básicas de física en relación con la trayectoria formativa en las carreras de grado y licenciatura en física. Se trata de un estudio de caso realizado en una universidad pública brasileña, realizado en forma de una investigación cuantitativa, longitudinal, que analizó información sobre disciplinas de física básica ofrecidas en el período 2000-2019. Los datos fueron organizados y analizados a partir de tres ejes principales: número de inscripciones en la disciplina; número de estudiantes aprobados; y tasa de aprobación. Se concluye que el desempeño de los estudiantes en estas disciplinas no mejora con el tiempo de permanencia en el curso, corroborando la baja eficiencia de los cursos de licenciatura en física para la formación de nuevos profesionales. Los resultados también indican la necesidad de reflexiones más amplias y profundas sobre la organización curricular y la forma de ofrecer las disciplinas de física básica que integran los planes de estudio de los cursos de grado en física, con el fin de formar más y mejor.

Palabras clave: Graduado en física. Tasa de aprobación. Disciplinas de física general.

\section{Introdução}

Já faz tempo que a evasão nos cursos de graduação em física vem mobilizando discussões e preocupando a comunidade científica e educacional brasileira. Em 2005, a necessidade de aumentar o número de professores formados em física foi tema de debate no evento: "Ensino de Física: Reflexões”, realizado pela Sociedade Brasileira de Física (SBF). Naquela época, Borges (2006) afirmava que não bastava aumentar o número de professores formados, mas que era imprescindível melhorar a formação inicial em Física. Borges (2006) também argumentou sobre a necessidade de articulação entre as pesquisas em educação e as pesquisas em ensino desenvolvidas por físicos renomados - citando o exemplo de Carl Wieman, prêmio Nobel de física em 2001 - como forma de promover mudanças mais significativas no modo de ensinar física nos cursos de graduação. A ideia central de seu argumento era em favor da melhoria da 
qualidade do ensino nas disciplinas de física básica da graduação (bacharelados e licenciaturas) para promover uma melhor formação inicial dos professores de física. Sobre essa necessidade, a síntese do evento, referente à formação de professores, relata que:

Existe um grande déficit de professores, em quantidade e qualidade, nos diferentes níveis de ensino. A reforma universitária de 1968 priorizou a constituição de quadros de pesquisadores nas universidades públicas. De fato, o mote da época era "precisamos formar uma geração de pesquisadores". Esse objetivo foi atingido e o mote agora precisa ser mudado para "precisamos formar uma geração de docentes universitários que, além de bons pesquisadores tenham também habilidade para as questões de ensino, sociais e nacionais". Esse deveria ser um caminho para resolver a questão de formação de professores da educação básica, qual seja, a de desenvolver uma sensibilidade da questão junto ao quadro de atuais pesquisadores das universidades. A prática e o rigor científico podem agora ser transferidos para a questão de ensino de forma abrangente. (SBF, 2005, p.2-3).

No cenário dessas perspectivas, o Brasil vivenciou na primeira década deste século um programa de Reestruturação e Expansão das Universidades Federais Brasileiras (REUNI), sem precedentes na história do país. Uma das metas globais do REUNI era atingir uma taxa de conclusão média de noventa por cento nos cursos de graduação presenciais. Além disso, o programa previa ainda o aumento de vagas ofertadas nas universidades, principalmente no turno noturno.

Era de se esperar que tal iniciativa trouxesse um alento para as áreas de graduação consideradas críticas, como a de formação de professores de física. Levantamentos realizados naquela época (FERRAZ, 2008) indicavam um déficit de 371 mil professores com licenciatura específica em todo país. Desse total, 56 mil eram da área de ensino de física. Para atender essa demanda, houve um aumento significativo na oferta de cursos de licenciatura em física, que passaram a ser ministrados também por Institutos Federais de Educação Tecnológica e na modalidade de Educação à Distância (EaD), em todos os estados da federação, com o propósito de suprir a demanda por professores com habilitação específica nessa área. Porém, o alento não veio da forma esperada.

Dados do Censo da Educação Superior (BRASIL, 2013) mostram que no período de 2001 a 2013 dos cerca de 101 mil alunos que ingressaram nos cursos de licenciatura em física apenas 23,4 mil concluíram a graduação. O que remete a uma taxa de conclusão média de pouco mais de $20 \%$. Esse resultado indica que ainda estamos muito longe de superar o déficit mencionado, e coloca em xeque nossa capacidade de formar novos professores de física. O número de vagas aumentou de forma expressiva, mas o aproveitamento dos alunos nos cursos de licenciatura em física continua muito ruim. 
Quais os motivos de uma taxa de conclusão média tão baixa? Vários estudos têm abordado essa questão (BARROSO e FALCÃO, 2004; LIMA e ALVES, 2006; GOBARA e GARCIA, 2007; ALMEIDA e SCHIMIGUEL, 2011; DE ATAÍDE; LIMA; DE OLIVEIRA ALVES, 2006; LIMA JR.; OSTERMANN; REZENDE, 2012; OLIVEIRA e SILVA, 2020; LIMA JR, et al, 2020). A maioria deles tem como foco a evasão e os motivos que levam os alunos ao abandono dos cursos. Os resultados indicam que a evasão é maior no início do curso, normalmente decorrente do fracasso em disciplinas introdutórias de Física e de Cálculo (BARROSO e FALCÃO, 2004). Também indicam problemas relacionados à austeridade da organização curricular (LIMA JR, et al., 2020); e que, por motivos de reprovações, os estudantes que conseguem obter o diploma acabam permanecendo no curso por um tempo muito maior que o esperado (LIMA JR. e OSTERMANN, 2012).

A cultura da reprovação é altamente alardeada nos cursos de Ciências Exatas. Seja pela suposta falta de preparo e maturidade dos alunos, ou pela suposta complexidade das disciplinas introdutórias de Física e de Cálculo. Estudo realizado por Lima Jr. et al. (2020, p.15) indica que a reprovação em massa no primeiro semestre desses cursos "é tão regular que já costuma ser considerada 'natural', sem, contudo, deixar de apresentar efeitos desintegradores para os alunos". De acordo com os autores, os estudantes "apontam que a reprovação nas disciplinas de primeiro semestre produz isolamento e constrangimento, prejudicando as experiências de integração social" (LIMA JR, et al., 2020, p.16). Fato que contribui para o abandono precoce do curso.

O senso comum, que permeia o universo dos cursos de graduação em física, coaduna com a ideia de que a reprovação, às vezes, é necessária para que o aluno atinja a maturidade imprescindível para dar continuidade ao curso. Porém, a hipótese que norteia o desenvolvimento deste estudo é de que o desempenho dos alunos em disciplinas de física básica não melhora com o tempo de permanência no curso. Para isso, desenvolvemos uma pesquisa quantitativa, longitudinal, com o objetivo de analisar e traçar um panorama dos resultados obtidos por estudantes, em disciplinas de física básica, nos cursos de bacharelado e licenciatura em física de uma universidade pública federal, no período de 2000 a 2019.

\section{Desenvolvimento}

Com intuito de buscar possíveis respostas e tecer algumas reflexões sobre o problema recorrente do baixo aproveitamento dos estudantes na graduação em física, procuramos analisar, de forma quantitativa, os resultados dos estudantes em disciplinas de física básica de um curso de graduação em física (bacharelado e licenciatura). Estamos cientes de que a abordagem quantitativa adotada neste estudo não é suficiente para tratar a complexidade do tema investigado. Porém, os dados e as análises realizadas ajudam a refletir sobre os motivos da baixa eficiência dos cursos 
de graduação em física, e servem de alerta para a necessidade de uma reflexão mais ampla a respeito da formação de professores de física no Brasil.

A pesquisa foi desenvolvida em uma Instituição de Ensino Superior (IES), pública federal, de um município de porte médio da região sudeste do Brasil. $\mathrm{O}$ ensino de física nessa instituição acompanha sua própria criação, em 1960. Inicialmente, a física era ministrada nos cursos de Engenharia e mais tarde passou a integrar os cursos de Licenciatura em Física (1970) e de Bacharelado em Física (1984), ambos com duração sugerida de oito períodos (4 anos). Mais recentemente foram criados os cursos de Licenciatura em Física a Distância (2009) e a Licenciatura em Física Noturna (2011), cujas análises comparativas não serão objetos deste trabalho.

A síntese de dados foi feita para as disciplinas de Física Geral I, II e III, Mecânica Clássica I, Física Moderna, Mecânica Quântica II e Instrumentação para Ensino de Física II. A escolha dessas disciplinas decorre do fato de as três primeiras serem disciplinas básicas comuns aos cursos da área de ciências exatas e tecnológicas, incluindo as graduações em Física (licenciatura e bacharelado). Mecânica Clássica I e Física Moderna são disciplinas exclusivas da licenciatura e do bacharelado em Física, geralmente cursadas no $4^{\circ}$ e no $5^{\circ}$ período, respectivamente, com ressalvas que serão feitas mais adiante. Mecânica Quântica é exclusiva do bacharelado em física e Instrumentação para Ensino de Física II é exclusiva da licenciatura em física, ambas cursadas mais no final dos cursos.

Todas as disciplinas analisadas foram ministradas por docentes do Departamento de Física (DF) da IES. As informações utilizadas foram coletadas no módulo de ensino do Sistema Integrado de Gestão Acadêmica (SIGA) a partir dos registros dos planos departamentais do DF, das notas dos estudantes e das turmas cadastradas no sistema. Tomado como principal fonte de dados, o SIGA é um sistema relativamente novo na IES e, por isso, não possui informações anteriores ao ano 2000 .

Os dados coletados foram traduzidos em gráficos que incluem a taxa de aprovação (TX) dos estudantes e o número de matrículas (MAT) na disciplina. Em alguns casos há também o número de estudantes aprovados na disciplina (AP). O índice TX é calculado pela razão AP/ MAT em porcentagem.

Até 2008 o ingresso na graduação em física na IES era semestral. A partir de 2009, com a implantação do REUNI, a entrada passou a ser anual, sendo no $1^{\circ}$ semestre para o Bacharelado Interdisciplinar em Ciências Exatas (BI-CE) e no $2^{\circ}$ semestre para a Licenciatura Noturna em Física. Esta somente a partir de 2011.

A partir de 2009, o ingresso na área de Ciências Exatas na IES passou a ocorrer apenas por meio do BI-CE, que é designado como $1^{\circ}$ ciclo de formação superior, e confere certificação 
(diploma de graduação) aos alunos em um tempo sugerido de seis períodos (três anos). Essa nova estrutura curricular extinguiu as entradas tradicionais nos cursos de Matemática, Física, Estatística, Ciência da Computação e Química, que passaram a ser designados como $2^{\circ}$ ciclo de formação, e só podem ser cursados, oficialmente, depois da conclusão do BI-CE. A disputa pelas vagas no $2^{\circ}$ ciclo é realizada por meio da análise do rendimento escolar do estudante a partir do $3^{\circ}$ período do BI-CE.

Por causa dessa dinâmica de vagas, tornou-se muito difícil distinguir, formalmente, entre os ingressantes no BI-CE, os estudantes que pretendem cursar física. Essa distinção só pode ser feita, com alguma cautela, a partir da análise do percurso formativo indicado no histórico escolar do estudante. Em função da diversidade de percursos formativos, também é difícil fazer distinção entre os estudantes do bacharelado e da licenciatura em física. Tal distinção só se torna definitiva na inscrição para a colação de grau, que é independente nos dois cursos.

A partir de 2013 houve uma mudança na distribuição de vagas do BI-CE. Das 55 vagas destinadas ao curso de Física, 25 passaram a ser disponibilizadas, como vagas declaradas em Física, para candidatos do Sistema Seletivo Unificado (SiSU) e do Programa de Ingresso Seletivo Misto (PISM) - processo seletivo próprio da IES. Com isso, estudantes ingressantes por meio de um desses processos já podem ser identificados como graduandos em Física desde o início do curso. Porém, ainda assim, continua não sendo possível a distinção entre licenciandos e bacharelandos antes da colação de grau.

\section{Resultados e discussão}

Nesta seção apresentamos a análise dos resultados dos estudantes nas disciplinas de Física Geral I, II e II; Física Moderna; Mecânica Clássica I; Mecânica Quântica II e Instrumentação para o Ensino de Física II. Os gráficos apresentados incluem dados de todas as matrículas, em todas as turmas, das disciplinas indicadas, incluindo os dois semestres letivos anuais.

\section{Análise das disciplinas de Física Geral: Física I, Física II e Física III}

Nas disciplinas de Física I, II e III têm sido adotados com frequência os livros-textos da coleção do Sears e Zemansky, respectivamente os volumes 1, 2 e 3. Quanto à metodologia de ensino, prevalecem as aulas tradicionais expositivas. Durante o período deste estudo, algumas metodologias alternativas foram testadas. Por exemplo, em meados de 2001 foi aplicada a metodologia dos Tutoriais de Física (McDERMOTT e SHAFFER, 2002) em todas as turmas de 
Física I e, durante alguns anos, até meados 2006, foi aplicado o método Keller (1972) em todas as turmas de Física I, II e III. Nos demais períodos vigorou, fundamentalmente, o ensino tradicional, baseado em aulas expositivas. As ementas das disciplinas não sofreram mudanças significativas no período do estudo. O Gráfico 1 mostra as taxas de aprovação anuais nessas disciplinas.

Gráfico 1. Taxa de aprovação (TX) anual para as disciplinas Física I, II e III.

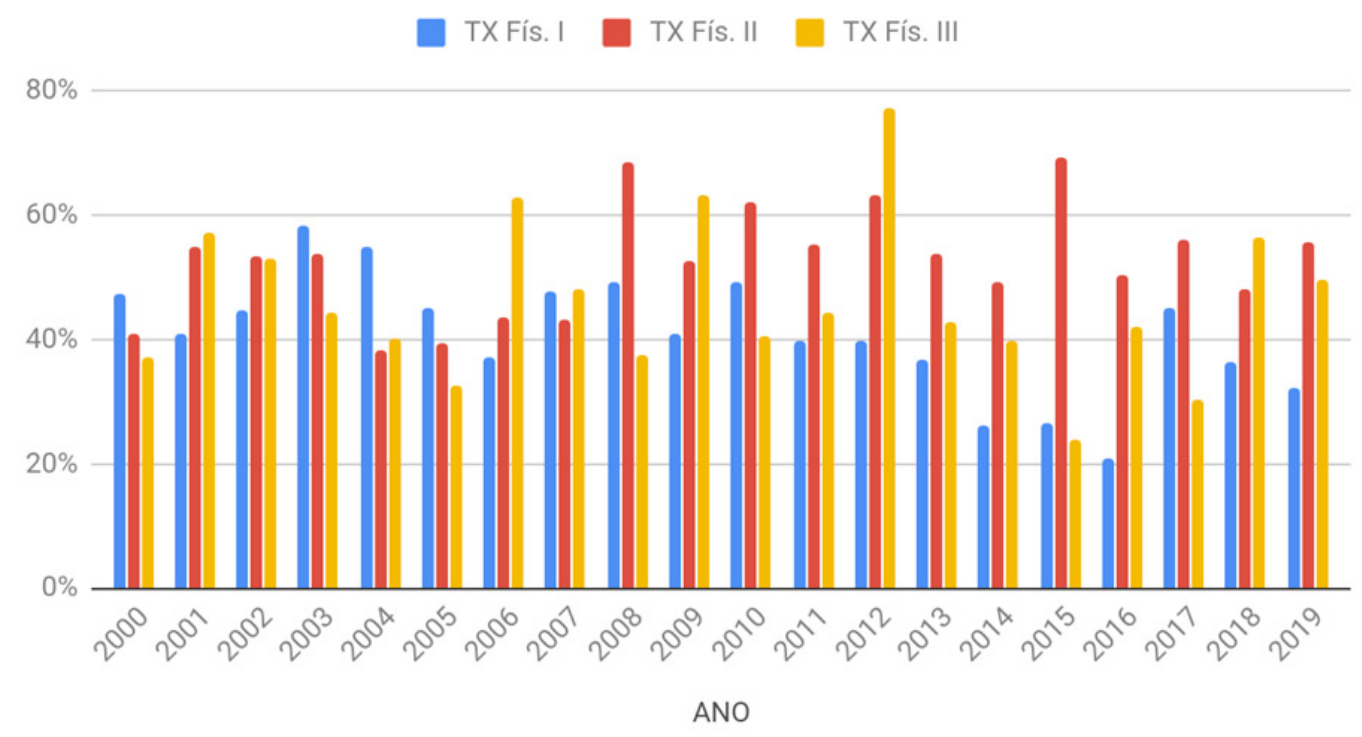

Fonte: Elaborado pelos Autores, 2021.

Nota-se uma significativa variação nas taxas de aprovação (TX) ao longo do período considerado. Física I tem TX de 41\% $\pm 10 \%$ (com valores mínimo e máximo respectivamente em $21 \%$ e 58\%), Física II tem 52\% \pm 9\% (mínimo de 38\% e máximo de 69\%), e Física III tem 46\% $\pm 13 \%$ (mínimo de 24\% e máximo de 77\%). Observa-se que a aplicação de metodologias alternativas (tutorias de física e método Keller) no período de 2001 a 2006 não surtiu efeito nas taxas de aprovação. Nesse período, em 2004, ocorreu ainda uma mudança no critério de aprovação, que alterou a nota mínima de 70 para 60. Mas isso também não trouxe modificações significativas nas taxas de aprovação.

Analisando o Gráfico 1, pode-se observar que a baixa taxa de aprovação em Física I, não implica em uma melhora significativa no aproveitamento dos alunos em Física II. Isso também vale para a disciplina de Física III em relação à Física II. Ou seja, as taxas de aprovação continuam baixas, mesmo após os alunos terem sido aprovados em uma ou duas disciplinas de física básica.

Até 2008 a disciplina de Física I era recomendada no $1^{\circ}$ período de todos os cursos de Ciências Exatas e Engenharias. Com a introdução do BI-CE, em 2009, ela passou a ser recomendada no $2^{\circ}$ período de todos os cursos. Até 2014, inclusive, Física I não tinha disciplinas de 
pré-requisitos. A partir de 2015 a disciplina Cálculo I foi incluída como pré-requisito de Física I. A Física II tem a Física I como pré-requisito, e a Física III tem a Física II como pré-requisito. A inclusão de Cálculo como pré-requisito para Física I a partir de 2015 surtiu um efeito relativo no aumento da taxa de aprovação somente a partir de 2017. Entretanto, entendemos que esse efeito é decorrente de uma redução expressiva no número de matrículas em Física I, a partir de 2016 (Gráfico 2), provavelmente em decorrência das reprovações em Cálculo. Ou seja, nesse novo cenário a disciplina de Cálculo passou a servir de "filtro", barrando uma quantidade expressiva de estudantes que antes cursavam Física I. Mesmo assim, a taxa média de aprovação se manteve em torno de $40 \%$.

Gráfico 2. Matrículas anuais em Física I, II e III.

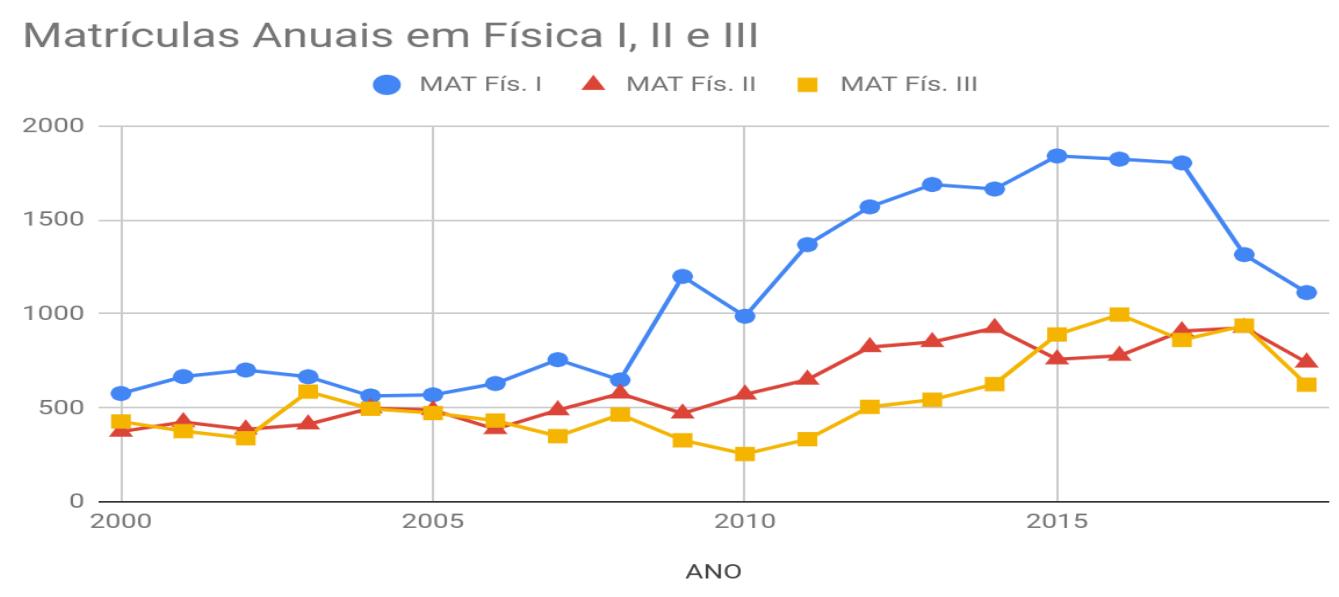

Fonte: Elaborado pelos Autores, 2021.

O Gráfico 2 mostra também um pico de matrículas em Física I em 2009. Isso se deve ao efeito do REUNI na IES, que duplicou a oferta de vagas nessa disciplina. É importante notar, na comparação dos Gráficos 1 e 2, que o pico de matrículas em Física I implicou em taxas de aprovação cada vez menores, até 2016. Isso também pode ser notado pelo fato de o aumento nas matrículas em Física I não ter seguido na mesma proporção nas disciplinas de Física II e III. O que nos faz retomar o argumento apresentado no início deste artigo de que o aumento de vagas não implica diretamente em mais estudantes formados.

A partir de 2010 houve um crescimento significativo no número de matrículas nas disciplinas de física geral, atingindo o pico em 2015. Desde então esse número vem caindo, mais expressivamente a partir de 2018.

É importante salientar que em 2009 o número de vagas para ingressantes no BI-CE foi de 325. Esse número representa mais que o dobro do ano anterior, quando eram 165 vagas somados 
os cursos de Física, Química, Matemática, Estatística e Computação. A oferta de vagas aumentou para 355 em 2010, e para 405 em 2011, com a inclusão dos cursos de Engenharias Elétrica e Mecânica no BI-CE. A partir daí o número de vagas para ingressantes não se alterou mais.

O crescimento no número de vagas poderia até sugerir uma justificativa para as baixas taxas de aprovação nas disciplinas de física geral, ocasionadas pelo ingresso de estudantes ainda menos preparados para as áreas de ciências exatas, atraídos pela grande oferta de vagas e pela baixa concorrência no processo seletivo para o BI-CE. Porém, retomando o Gráfico 1, percebe-se que não houve alterações significativas nessas taxas.

Ainda em relação às disciplinas de Física Geral, outro aspecto que merece atenção é a relação quantidade de alunos/turma. O Gráfico 3 mostra o número de turmas anuais das disciplinas Física I, II e III, no período do estudo.

Gráfico 3. Número de turmas anuais abertas para as disciplinas de Física I, II e III.

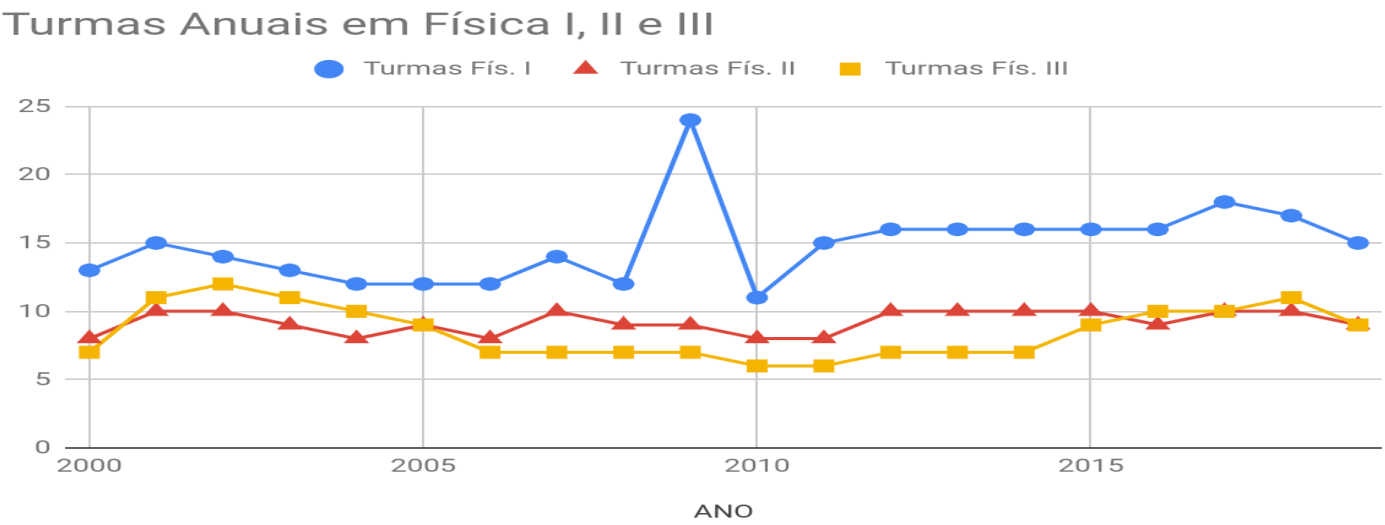

Fonte: Elaborado pelos Autores, 2021.

O pico de turmas em 2009 demanda justificativa. Naquele ano ainda não estavam prontas as salas de aula do projeto REUNI, previstas para 100 alunos. Com isso, as turmas do novo bacharelado tiveram que ser lotadas nas antigas salas com capacidade para até 60 alunos. Com isso, houve, de fato, o oferecimento do dobro de turmas (24) em relação aos anos anterior (12 em 2008) e posterior (11 em 2010). A partir de 2010 as salas com 100 vagas passaram a ser utilizadas, o que implicou na redução do número de turmas. Entendemos que tal configuração agrava ainda mais a situação das baixas taxas de aprovação, haja vista que intensifica o problema da necessidade de atenção aos alunos que apresentam dificuldades para acompanhar as disciplinas de física geral.

Entre 2012 e 2015, o número de turmas anuais ficou estável, em torno de 16 para Física I, e 10 para Física II e III. Também é importante ressaltar que a partir de 2010 passou-se a ofertar 
uma turma especial de Física I, por semestre, com aulas não presenciais e até 200 vagas. Para Física II foram ofertadas quatro turmas especiais, no período analisado, e para Física III foram ofertadas sete turmas especiais. A oferta dessas turmas tinha por objetivo equacionar problemas decorrentes do grande volume de retenção nessas disciplinas. Porém, esta ação também não surtiu muito efeito e a procura por turmas especiais teve queda significativa nos últimos anos analisados. Em 2019 apenas uma turma especial de Física I foi oferecida. As turmas especiais foram computadas nos dados do Gráfico 3.

Os dados apresentados nos Gráficos 1, 2 e 3 sugerem que o aumento quantitativo do número de vagas nas disciplinas de física geral não foi acompanhado de uma melhoria qualitativa na forma de oferta dessas disciplinas. Novos sujeitos passaram a ter acesso à graduação em ciências exatas agravando velhos problemas, como a reprovação em massa, referendada pela nítida queda na taxa de aprovação entre 2009 e 2016. Isso significa que as melhorias em infraestrutura (novas salas e laboratórios foram construídos), bem como a mudança curricular proporcionada pelo REUNI com a implantação do BI-CE, não implicaram na necessária melhoria na qualidade dos cursos e na forma de oferta das disciplinas, no sentido de atender a maior diversidade de perfis e percursos formativos dos novos estudantes que passaram a ter acesso às universidades.

Consideramos que a prevalência de uma baixa taxa de aprovação nas disciplinas de física geral é reveladora de efeitos perversos que um aumento expressivo da quantidade de vagas, sem a devida preocupação com os aspectos metodológicos e organizacionais, ocasiona. O que nos faz refletir sobre as necessidades específicas da diversidade de estudantes que hoje ingressam nos cursos superiores.

Um estudo realizado sobre condicionantes sociais da evasão e retenção em cursos de graduação em Física à luz da sociologia de Bourdieu (LIMA JR.; OSTERMANN; REZENDE, 2012, p. 56) constatou que "a posição do estudante na estrutura das relações de classe, embora seja fundamental para determinar o sucesso e a trajetória escolar em vários contextos do sistema educacional, não está relacionada à evasão ou diplomação no caso dos cursos de Física." Isso significa que na graduação em Física parece prevalecer o mito de que só aqueles que têm "vocação" sobrevivem. Porém, o mesmo estudo indica que "alunos de classes mais abastadas (tanto em matéria de recursos econômicos quanto em matéria de posse de títulos escolares) ficam retidos por menos tempo nos cursos de Física para obtenção do diploma”.

Os resultados apresentados até aqui nos fazem refletir ainda sobre o descompasso entre a lógica que orienta as políticas públicas - que tendem a simplificar a solução da carência de profissionais com o aumento do número de vagas, e de programas de acesso ao ensino superior 
e a lógica interna que orienta a organização dos cursos de graduação - geralmente embasada em preconcepções pautadas em um perfil desejável e idealizado de estudante. No caso da graduação em física, nos parece que esse descompasso, quase sempre, preconiza uma correlação direta entre a falta de preparo dos estudantes oriundos da educação básica e as baixas taxas de aprovação nas disciplinas de física geral. No entanto, essa lógica, que à primeira vista pode parecer óbvia, não se sustenta. Conforme veremos nas seções seguintes, o acúmulo de reprovações e o alto índice de abandono nas disciplinas de física geral não garante o sucesso daqueles que conseguem superar as barreiras dessas disciplinas e dar continuidade ao curso.

\section{Análise da disciplina Física Moderna}

Adisciplina Física Moderna ministrada no curso analisado é mais comumente denominada de Estrutura da Matéria em outras instituições. Sua ementa abrange a fenomenologia básica que levou ao surgimento da Mecânica Quântica e da Relatividade Especial. Essa disciplina é recomendada no $5^{\circ}$ período dos cursos de Física (licenciatura e bacharelado). É uma das primeiras disciplinas exclusivas para quem quer seguir na graduação em física, e consta dos currículos de Física da instituição investigada somente a partir de 2003. Desde então tem sido ofertada regularmente.

O Gráfico 4 mostra o número de matrículas (MAT) e o número de aprovados (AP) anuais em Física Moderna.

Gráfico 4. Matriculados (MAT) e aprovados (AP) anuais em Física Moderna.

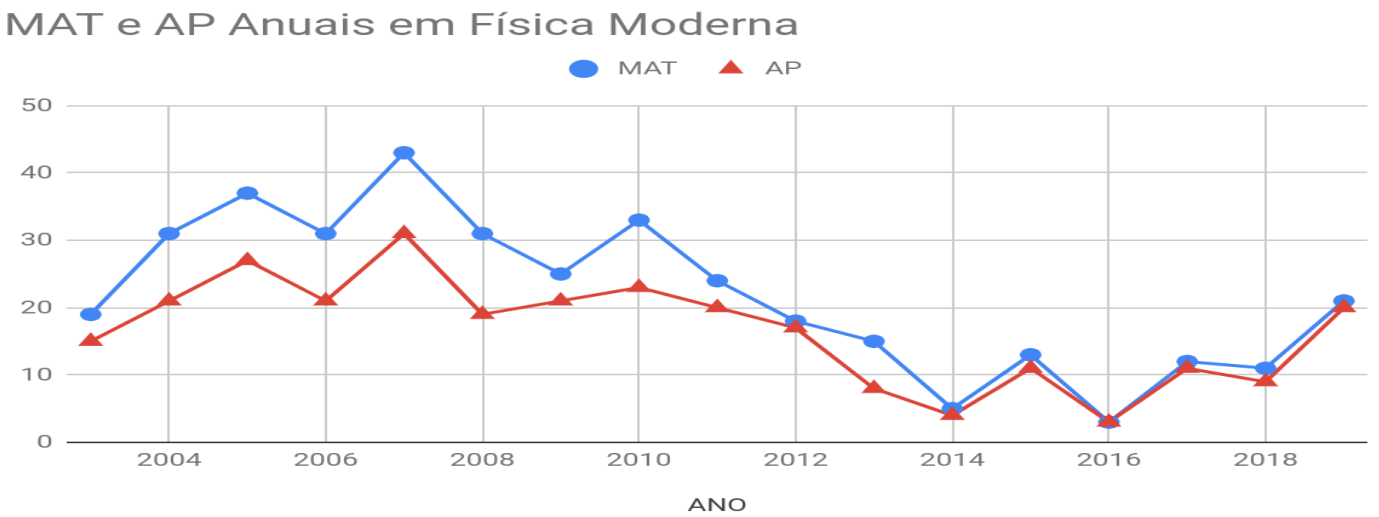

Fonte: Elaborado pelos Autores, 2021. 
O número de matriculados anual médio é de $21 \pm 11$, mínimo de 03 e máximo de 43 alunos. O número anual médio de aprovados é de $17 \pm 8$, mínimo de 03 e máximo de 31 alunos. O que remete a uma taxa de aprovação média de $80 \%$.

Nota-se que a partir de 2012 houve uma queda expressiva no número de estudantes matriculados em Física Moderna, abaixo das médias históricas, registradas até então. Esse fato reflete uma clara tendência de os estudantes de ciências exatas evitarem seguir na graduação em Física dando preferência a outros cursos do BI-CE, principalmente os de Engenharia, o que referenda outros estudos já realizados sobre a temática da evasão na graduação em física (FERNANDES, et al., 2020). Consideramos que tal tendência seja resultado da combinação de diversos fatores, entre os quais ressaltamos o baixo aproveitamento dos estudantes nas disciplinas de física geral, a falta de identidade profissional provocada pela implantação do BI-CE, a partir de 2009, e a baixa atratividade da carreira de físico (bacharel e educador), que no mercado de trabalho tem poucas chances de exercer outra profissão que não seja o magistério.

Vale notar que a criação de vagas declaradas em Física, a partir de 2013, parece ter ajudado a minimizar a falta de identidade com o curso e ter contribuído para um ligeiro aumento das matrículas em Física Moderna a partir de 2017.

\section{Análise da disciplina Mecânica Clássica I}

A disciplina Mecânica Clássica I é obrigatória para o bacharelado e a licenciatura em Física. Apesar de ser recomendada no $4^{\circ}$ período de ambos os cursos, ela é efetivamente cursada pelos estudantes em momentos bastante distintos. Sua ementa trata do estudo do movimento em diversas situações, incluindo sistemas de partículas, oscilações, rotações e forças centrais, utilizando-se de ferramentas matemáticas como cálculo avançado e equações diferenciais ordinárias.

No bacharelado em física, Mecânica Clássica I é pré-requisito somente para Mecânica Clássica II (recomendada no $5^{\circ}$ período). Já para licenciatura, ela não é pré-requisito para nenhuma outra disciplina, o que permite que seja cursada, mais efetivamente, no último ou no penúltimo período do curso pela maioria dos estudantes. O Gráfico 5 apresenta o número de matrículas e número de aprovados anualmente nessa disciplina. 
Gráfico 5. Matriculados (MAT) e aprovados (AP) anuais em Mecânica Clássica I.

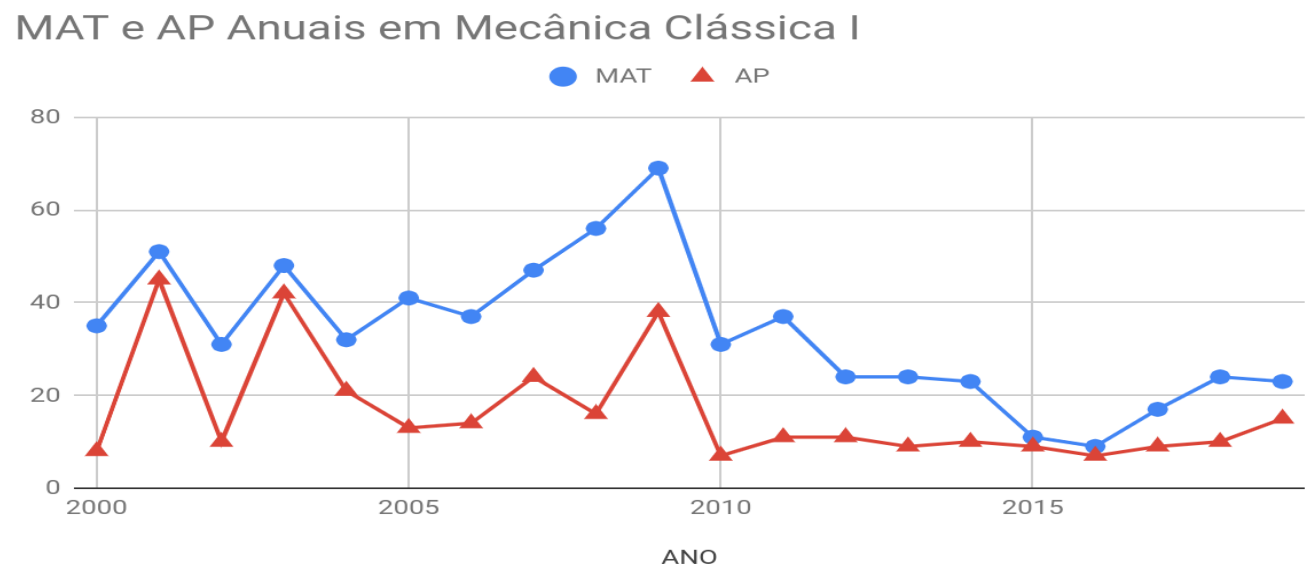

Fonte: Elaborado pelos Autores, 2021.

Observa-se uma grande variação nos dados do período considerado. O número médio de matrículas anuais foi de $34 \pm 15$, mínimo de 09 e máximo de 69 . O número médio anual de aprovados foi de $16 \pm 12$, mínimo de 07 e máximo de 45 . Essa disciplina foi oferecida em quase todos os semestres, com exceções de 2000.1 e 2002.1. Nela, a taxa de aprovação média, de 49\%, se aproxima novamente das apresentadas nas disciplinas de física geral. Por se tratar de uma disciplina de aprofundamento dos conteúdos de Física I, e pelo fato de a maioria dos estudantes cursá-la já no final da graduação, era de se esperar melhores resultados. Porém, a necessidade de um tratamento matemático mais elaborado e da aplicação de conteúdos adquiridos em outras disciplinas, revela a fragilidade formativa da fragmentada trajetória que os alunos da graduação em física seguem.

Assim, como vem ocorrendo na disciplina de Física Moderna, observa-se que em Mecânica Clássica I o número médio de matriculados diminuiu, expressivamente, a partir da implantação do BI-CE, e está muito abaixo da média histórica. O que mais uma vez referenda o baixo interesse dos estudantes de ciências exatas pela graduação em física.

\section{Análise da disciplina Mecânica Quântica II}

A disciplina Mecânica Quântica II é sugerida no $7^{\circ}$ período do bacharelado em física. Por não ser pré-requisito de nenhuma outra disciplina, acaba sendo cursada, de fato, no último período do curso. Sua ementa abrange o estudo de spins, teoria de perturbação, espalhamento e distribuições de Fermi e Bose. 
O Gráfico 6 apresenta o número de matriculados (MAT) e número de aprovados (AP) anual em Mecânica Quântica II.

Gráfico 6. Matriculados (MAT) e aprovados (AP) anuais em Mecânica Quântica II.

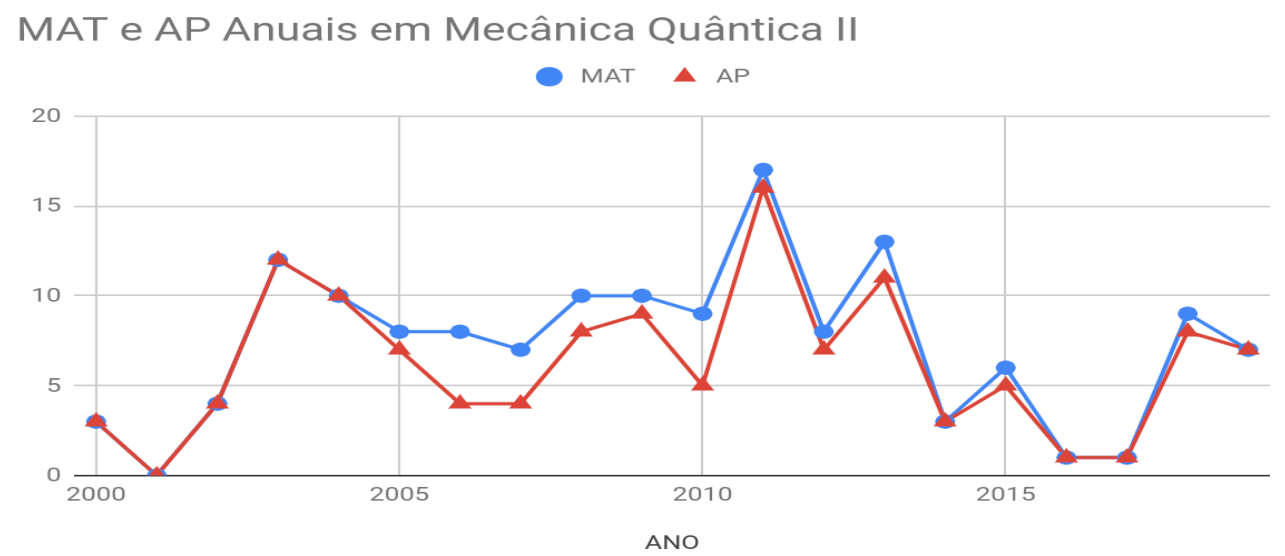

Fonte: Elaborado pelos Autores, 2021.

O número médio anual de alunos matriculados é de $7 \pm 4$, mínimo de 1 e máximo de 17 , e o número médio de aprovados é de $6 \pm 4$, com mínimo de 1 e máximo de 16 , o que remete a uma taxa média de aprovação de $86 \%$. A razão de encontrarmos uma alta taxa de aprovação nessa disciplina pode estar associada ao fato de ela ser cursada por estudantes do bacharelado, em final de graduação, que, pela falta de perspectiva de ingresso no mercado de trabalho, já demonstram certo interesse em ingressar no mestrado em física. Por isso, têm uma preocupação maior com seu histórico escolar, pensando na seleção futura. Além disso, na fase do curso em que a disciplina é ofertada, a maioria dos alunos já participou de algum programa de iniciação científica e já tem sua monografia de conclusão de curso bem encaminhada. Ou seja, aqui que se revela, em tese, os poucos sobreviventes com potencial para seguir na carreira de físico.

\section{Análise da disciplina Instrumentação para o Ensino de Física II}

A disciplina de Instrumentação para o Ensino de Física II é recomendada no $8^{\circ}$ período do curso de licenciatura em física. Entretanto, pelo fato de não ter como pré-requisitos algumas disciplinas de formação profissional específica, tais como Mecânica Clássica I, Termodinâmica ou Teoria Eletromagnética I, quase sempre acaba sendo antecipada pelos alunos da licenciatura.

O Gráfico 7 (mostrado na página seguinte) apresenta o número de matriculados (MAT) e o número de aprovados (AP) anual em Instrumentação para o Ensino de Física II.

O número médio de matrículas anuais em Instrumentação para o Ensino de Física II é de $13 \pm 9$, mínimo de 1 e máximo de 35 , e o número de aprovados anual médio é de $12 \pm 8$, 
mínimo de 1 e máximo de 27, o que remete uma taxa de aprovação média de 92\%. Aqui também consideramos razoável encontrarmos uma alta taxa de aprovação. Trata-se de uma disciplina cursada por alunos que, geralmente, já são professores da rede pública ou particular e que já realizaram o Estágio Supervisionado para a licenciatura - ou estão cursando-o em paralelo com essa disciplina. Por isso, essa disciplina pode ser considerada um indicador prévio da escolha do aluno pela licenciatura em física e do interesse pela obtenção do diploma. O que poderá acarretar melhores condições de trabalho e melhores salários, quando efetivados nas escolas onde lecionam.

Gráfico 7. Matriculados (MAT) e aprovados (AP) anuais em Instrumentação para o Ensino de Física.

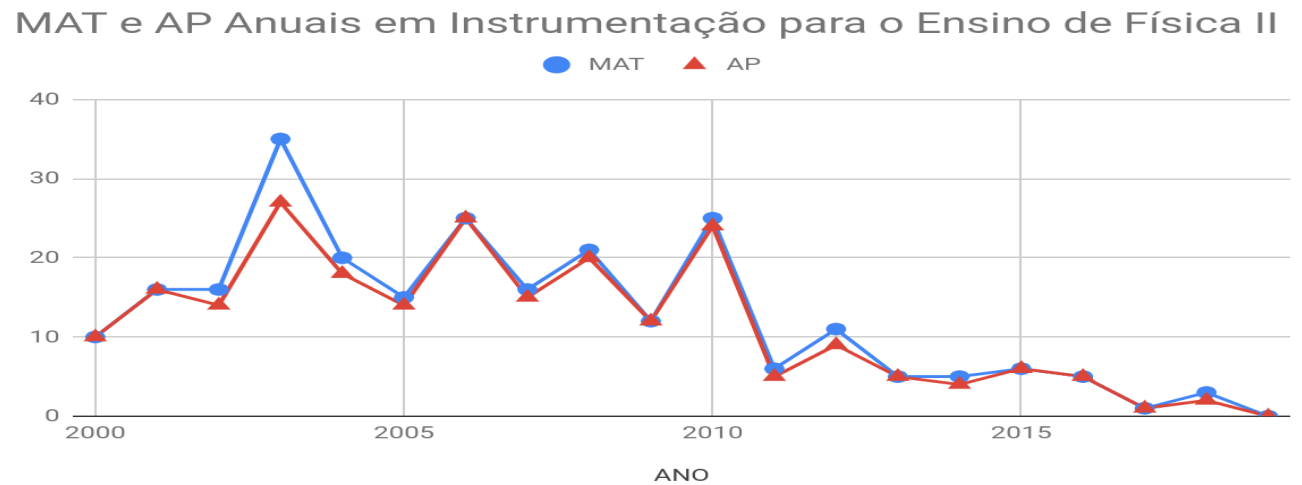

Fonte: Elaborado pelos Autores, 2021.

Temos aqui também um potencial indicador da carência de professores de física no mercado de trabalho. Nota-se, que há uma relativa estabilidade em torno de 20 alunos matriculados, em média, no período de 2002 até 2010. Entretanto, a partir de 2011 há uma queda acentuada e preocupante nesse número. Inversamente ao que ocorre em Mecânica Quântica II, a taxa de matrículas nessa disciplina a partir de 2011 correspondem aos menores valores da série histórica. Isso indica que o patamar estável em Física Moderna, entre 2008 e 2012, correspondeu a alunos que acabaram por optar, predominantemente, pelo bacharelado e não pela licenciatura. $\mathrm{O}$ que nos leva a acender mais um alerta: se o número de alunos que se interessam pela graduação em física vem caindo drasticamente, entre aqueles que se interessam pela licenciatura em física parece que essa queda pode ser ainda mais acentuada.

\section{Colação de Grau em Física}

Para finalizar este estudo incluímos os dados da Colação de Grau, quando é concedido ao estudante o título de bacharel ou licenciado em física. Consideramos esse dado como um parâmetro importante do retorno que a universidade dá à sociedade. A Gráfico 8 mostra a quan- 
tidade anual de alunos que concluíram a graduação em física (licenciatura e bacharelado), desde os primeiros licenciados em 1977, até 2017.

Gráfico 8. Colações de Grau em Bacharelado e Licenciatura em Física desde 1977 até 2017.

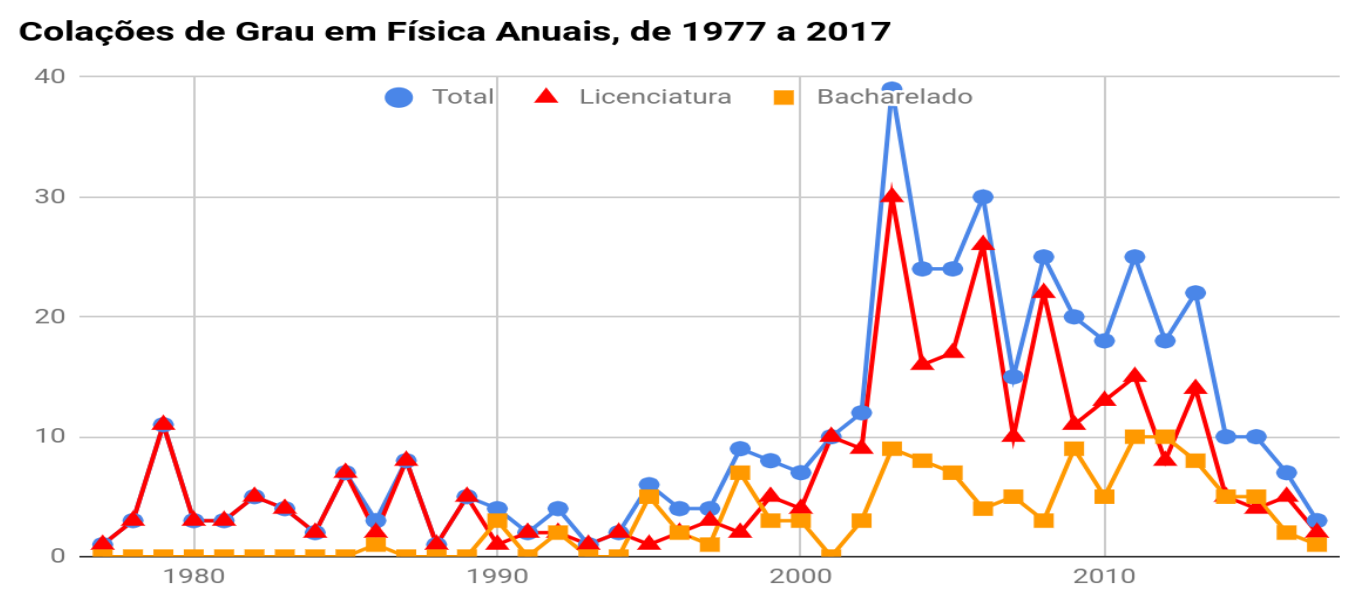

Fonte: Elaborado pelos Autores, 2021.

O total de diplomados com a licenciatura em física na universidade estudada, entre 1977 e 2017, foi de 298. No bacharelado em física, no período de 1986 a 2015, foram diplomados 121 alunos. Com isso, o total de diplomados em física, entre 1977 e 2017, foi de 419. Desse total, 42 alunos obtiveram dupla graduação em licenciatura e bacharelado. No Gráfico 9 destacamos o intervalo compreendido entre 2000 e 2017.

Gráfico 9. Colações de Grau em Bacharelado e Licenciatura em Física de 2000 até 2017.

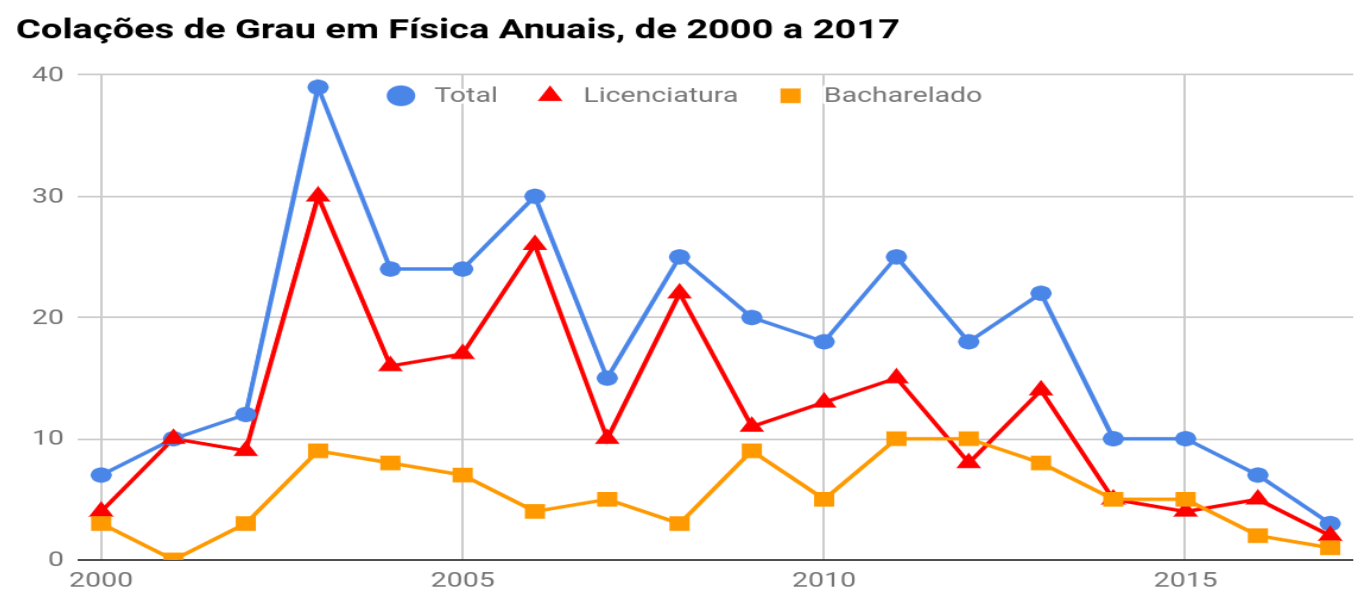

Fonte: Elaborado pelos Autores, 2021. 
$\mathrm{Na}$ análise desses gráficos, nota-se um aumento significativo no número de diplomados em física em 2003, particularmente na licenciatura em física. Tal fato pode estar relacionado à influência da Lei de Diretrizes e Bases da Educação Brasileira (Lei n ${ }^{\circ}$ 9.394, de 20 de dezembro de 1996), que estipula em seu Artigo 62 que "A formação de docentes para atuar na educação básica far-se-á em nível superior, em curso de licenciatura, de graduação plena...” (BRASIL, 1996, p. 20), o que demandou uma corrida de professores leigos pela habilitação específica nos anos posteriores. Entretanto, a partir de então, mesmo com a política de expansão universitária, observa-se uma queda lenta e contínua no número de graduados em física.

Observa-se ainda que número de novos bacharéis em física sempre se manteve abaixo de 10 por ano, e o de licenciados em física, que chegou a 30 em 2003, está se mantendo abaixo de 15 por ano desde 2009. Apesar de o número de estudantes cursando Física Moderna e Mecânica Clássica I ter aumentado ligeiramente nos últimos dois anos do estudo, a tendência indicada pelo número de matriculados em Instrumentação para o Ensino de Física II tende para uma queda ainda maior e preocupante no número de licenciados em física. A tendência sinalizada no Gráfico 9, a partir de 2015, é de menos de dez graduados em física por ano, incluindo licenciatura e bacharelado, número esse muito próximo aos das décadas de 1980 e 1990 . O que reforça a premissa da nossa reflexão de que o simples aumento do número de vagas não resolve o problema da carência de professores de Física.

\section{Considerações finais}

Manifestaremos aqui algumas preocupações e considerações a partir do estudo realizado. Inicialmente, entendemos que a leitura dos dados e as análises feitas devem ser relativizados por se tratar de um estudo de caso uma IES específica, situada em um dado contexto. Porém, outros estudos (ALMEIDA; SCHIMIGUEL, 2011; ATAÍDE; LIMA; ALVES, 2006; GOBARA; GARCIA, 2007; FERNANDES, et al, 2020) evidenciam que o que foi observado em relação às baixas taxas de aprovação e o grande número de abandono de disciplinas de física básica pode ser considerado bem próximo da realidade da maioria dos cursos de graduação em física ministrados nas universidades públicas brasileiras.

O projeto REUNI, a partir do qual foi implementado o curso de Bacharelado Interdisciplinar em Ciências Exatas (BI-CE) na instituição analisada, aumentou significativamente o número de vagas nos cursos superiores. Porém, para a graduação em física tal aumento não significou formar mais e nem melhor. À margem de todo investimento feito na contratação de novos professores, na construção de novas salas de aula e novos laboratórios de pesquisa e de 
ensino, e em projetos de ensino, pesquisa e extensão, a graduação em física continua gotejando o mesmo número de graduandos de décadas atrás. Além disso, o simples aumento das vagas trouxe consequências outras que ainda não foram devidamente analisadas, dentre as quais destacamos: a facilidade de ingresso versus a permanência no curso; o aumento do número de alunos por turma versus a qualidade do ensino ministrado; e a falta de identidade profissional gerada pelos cursos de bacharelados interdisciplinares.

Nesse sentido, gostaríamos de retomar o argumento do professor Borges (2006), apresentado no início deste artigo, em favor de um ensino científico para melhorar a qualidade das disciplinas de física básica ministradas na graduação em física. A tese central de seu argumento está na possibilidade de articulação entre as pesquisas em educação e as pesquisas em ensino desenvolvidas por físicos renomados. Para que essa articulação ocorra entendemos que o professor universitário precisa ser mais que um bom pesquisador. É necessário que ele se empenhe em atividades de ensino, tanto quanto em suas atividades de pesquisa. Que, a exemplo dos físicos citados por Borges, tenha interesse e disposição para transitar entre essas duas culturas. Que sejam ousados na proposição de mudanças nos cursos de graduação em física, que até hoje se espelham em matrizes curriculares com mais de meio século de existência. Que tenham coragem para rever ementas e reestruturar percursos formativos, em torno daquilo que seja realmente significativo, para atender as necessidades dos novos estudantes que hoje adentram as universidades em maior número e com trajetórias escolares muito mais diversas daquelas de há dez ou vinte anos atrás.

Para isso, é preciso priorizar percursos formativos menos acidentados, mas que possibilitem uma boa base em física. A qualidade que aqui defendemos não se consegue com o aumento nas reprovações ou com a simples criação de disciplinas de nivelamento. Conforme mostrado neste estudo, a sobrevivência nas disciplinas de física geral não é sinônima de melhor desempenho nas disciplinas específicas subsequentes da graduação em física.

Também nos preocupa o efeito danoso de estratégias que visam somente a otimização das estruturas e o aumento do número de vagas nos cursos de graduação. O modelo de bacharelado interdisciplinar adotado na instituição analisada, permitiu maior flexibilização nos percursos formativos a partir dos interesses estudantes, das oportunidades oferecidas durante o curso e do relacionamento com professores de diversos departamentos. À primeira vista, isso parece ser vantajoso quando comparado às estruturas curriculares engessadas que impedem ou desestimulam as mudanças, prendendo os alunos em processos formativos com os quais não se identificam. Porém, a atratividade gerada pelo BI-CE não se sustenta perante as dificuldades enfrentadas pelos estudantes nas disciplinas do $1^{\circ}$ ciclo. As baixas taxas de aprovação nas disciplinas de física 
geral contribuem para o elevado índice de evasão e colaboram para que a graduação em física seja evitada. Além disso, a oferta de disciplinas com turmas de 100 alunos, sem uma metodologia adequada, acentua ainda mais as dificuldades e as fragilidades formativas que os estudantes universitários trazem da educação básica.

É preocupante perceber que mesmo depois de mais de uma década de grandes investimentos, tendemos a continuar titulando o mesmo número reduzido de estudantes que conseguem sobreviver ao tortuoso percurso formativo da graduação em física. O caso é ainda mais grave quando se trata da licenciatura em física. Corroborando com os resultados deste estudo, dados do Censo da Educação Superior de 2018 (INEP, 2018) indicam que apenas 43,3\% dos professores que lecionam física no ensino médio possuem a licenciatura específica, e que a taxa de desistência dos estudantes que ingressam nas licenciaturas em física era 71,8\%, em 2016. De acordo com Tokarnia (2016), com base nesses números, seriam necessários cerca de 11 anos para que todos os professores de física tivessem a formação adequada. Conforme procuramos mostrar neste estudo, o problema central não está na falta de vagas, mas sim na baixa eficiência dos cursos existentes.

É claro que não podemos ser ingênuos de imputar a culpa dessa baixa eficiência apenas às questões metodológicas, curriculares e estruturais dos cursos. Sabemos que o desinteresse pela física, e mais especificamente pela licenciatura em física, se deve também a outros fatores externos, como os baixos salários praticados e as más condições de trabalho a que os professores da Educação Básica são submetidos. Em números atuais, o retorno financeiro de uma carreira técnica, como as de engenharias, por exemplo, pode ser muito mais vantajoso, e com uma formação menos onerosa, se comparada com a graduação em física.

Apesar disso, defendemos que é possível dar conta, minimamente, de uma formação adequada e de qualidade àqueles poucos alunos que buscam a graduação em física. Entendemos que a centralidade do problema não está em definir aquilo que deve ser ensinado - como nos faz crer as mudanças curriculares, geralmente apresentadas como propostas para o enfrentamento do problema - e sim no como e para quem devem ser direcionadas as disciplinas de física básica.

Em primeiro lugar, consideramos que não dá para conceber que uma mesma disciplina atenda às necessidades formativas de bacharéis e licenciados. Não se trata de ensinar mais ou menos física para um ou para outro. Há de se entender que são percursos formativos diferentes em suas finalidades e que o professor formador da graduação precisa ter clareza dessa diferença ao ensinar. Em segundo lugar, as metodologias adotadas devem ser coerentes com o perfil dos alunos e das turmas para as quais se leciona um determinado conteúdo. Um método de ensino aplicado a uma turma de 20 alunos não pode ser a mesmo para outra turma com 100 alunos. 
Para isso, conforme indicado por Borges (2006), o físico pesquisador do ensino superior - que também é professor - deve estar disposto a aprender novas metodologias de ensino, a entender como se articulam os processos de ensino e de aprendizagem. Nesse sentido, consideramos que o programa de Mestrado Nacional Profissional em Ensino de Física (MNPEF), instituído em 2013 pela Sociedade Brasileira de Física (SBF), além da qualificação dos professores de física da educação básica, vem cumprindo o importante papel de despertar o interesse dos físicos pesquisadores pelos processos educacionais.

Em terceiro lugar, entendemos que é preciso haver uma maior integração entre conteúdos teóricos, experimentais e procedimentais, e um uso mais efetivo dos recursos didáticos e das novas tecnologias de ensino, com ênfase na aquisição de conceitos físicos estruturantes e no desenvolvimento do pensamento científico. Isso pode ser dinamizado com a colaboração de estudantes seniores de graduação e de pós-graduação em atividades de acolhimento aos calouros, envolvendo não só as tradicionais monitorias, mas também um sistema de tutoria que possibilite o gerenciamento de grupos de estudos e o acompanhamento dos discentes, criando vínculos em torno de uma comunidade de ofício que ajude a fortalecer a identidade da graduação em física.

Por fim, mas não menos importante, não podemos deixar de mencionar a recente regulamentação da Base Nacional Comum Curricular (BNCC), que apresenta mudanças significativas na estrutura do Ensino Médio, que indicam uma necessária e completa reformulação na formação dos professores que atuam nas diferentes áreas das Ciências da Natureza e suas Tecnologias.

\section{Agradecimentos}

Agradecemos ao funcionário técnico administrativo Carlos Adolpho Pereira Junior, pela colaboração na coleta de informações no SIGA.

\section{Referências}

ALMEIDA, João B.; SCHIMIGUEL, Juliano. Avaliação sobre as causas da evasão escolar no ensino superior: estudo de caso no curso de licenciatura em física no Instituto Federal do Maranhão. Revista de Ensino de Ciências e Matemática, v. 2, n. 2, p. 167-178, 2011.

BARROSO, Marta F.; FALCÃO, Eliane BM. Evasão universitária: o caso do Instituto de Física da UFRJ. IX Encontro Nacional de Pesquisa em Ensino de Física, v. 9, p. 1-14, 2004.

BORGES, Oto. Formação inicial de professores de Física: formar mais! Formar melhor! Revista Brasileira de ensino de Física, v. 28, n. 2, p. 135-142, 2006.

BRASIL. Lei n 9.394/96. Lei de Diretrizes e Bases da Educação Nacional, de 20 de dezembro de 1996. Disponível em http://portal.mec.gov.br/seesp/arquivos/pdf/lei9394_ldbn1.pdf. Acesso em: 30/04/2021. 
DE ATAÍDE, Jair S. P.; LIMA, Lourivaldo Mota; DE OLIVEIRA ALVES, Edvaldo. A repetência e o abandono escolar no curso de licenciatura em física: um estudo de caso. Physicae, p. 21-32, 2006.

FERNANDES, João et al. Estudo da evasão dos estudantes de Licenciatura e Bacharelado em Física: uma análise à luz da Teoria do Sistema de Ensino de Bourdieu. Caderno Brasileiro de Ensino de Física, v. 37, n. 1, p. 105-126, 2020.

FERRAZ, Mariana. Procuram-se mestres. Ciência Hoje, v.42, p.48-51, julho, 2008.

GOBARA, Shirley T.; GARCIA, João R. B. As licenciaturas em física das universidades brasileiras: um diagnóstico da formação inicial de professores de física. Revista brasileira de ensino de física, v. 29, n. 4, p. 519-525, 2007.

INEP - INSTITUTO NACIONAL DE ESTUDOS E PESQUISAS EDUCACIONAIS ANÍSIO TEIXEIRA. Censo da Educação Superior 2017: divulgação dos principais resultados. Brasília, Inep, 2018. Disponível em: https://abmes.org.br/arquivos/documentos/apresentacao_ censo_superior2018.pdf. Acesso em 21/05/2020.

KELLER, Fred S. Adeus, Mestre! Ciência e Cultura, v. 24, p. 207-217, 1972.

LIMA JR, Paulo; OSTERMANN, Fernanda; REZENDE, Flavia. Análise dos condicionantes sociais da evasão e retenção em cursos de graduação em Física à luz da sociologia de Bourdieu. Revista Brasileira de Pesquisa em Educação em Ciências, v. 12, n. 1, p. 37-60, 2012.

MANCEBO, Deise; VALE, Andréa Araújo; MARTINS, Tânia Barbosa. Políticas de expansão da educação superior no Brasil 1995-2010. Revista brasileira de educação, v. 20, n. 60, p. 31-50, 2015.

McDERMOTT, Lillian C.; SHAFFER, Peter S. Tutorials in Introductory Physics, 1st Edition. Prentice Hall, New Jersey, 2002.

OLIVEIRA, Valéria Aparecida de; SILVA, André Coelho da. Uma revisão da literatura sobre a evasão discente nos cursos de licenciatura em física. Ensaio Pesquisa em Educação em Ciências (Belo Horizonte), v. 22, 2020.

SBF - SOCIEDADE BRASILEIRA DE FÍSICA. Ensino de Física: reflexões MEC/SBF. Brasília: UNB -11 e 12/08/2005. Disponível em: http://www.sbfisica.org.br/arquivos/reflexoes. pdf. Acesso em: 30/04/2021.

TOKARNIA, M. Agência Brasil. EBC. Disponível em: http://agenciabrasil.ebc.com.br/ print/1008557. Publicado em 28/03/2016. Acesso em: 11/04/2016.

Recebido: 20 de junho de 2021 .

Publicado: 14 de julho de 2021.

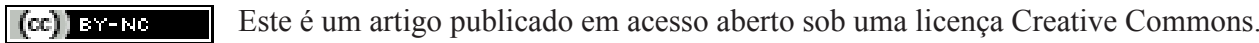

